\title{
The effect of a copper, selenium and cobalt soluble glass bolus on the trace element status of Bactrian camels*
}

\author{
Z.P. Liu ${ }^{1}$ and G.L. Xiong \\ College of Veterinary Medicine, Yangzhou University \\ Yangzhou, Jiangsu 225009, P.R. China
}

\begin{abstract}
The trial was carred out to evaluate the performance of a soluble glass copper, cobalt and selenium bolus for maintaining adequate levels of the three trace elements in Bactrian camels. The sixty Bactrian camels, 30 females and 30 castrated males, selected for the study were 2-13 years of age in Alashanyouqi County of Inner Mongolia and were allocated to two groups by restricted randomization. One group each had two $100 \mathrm{~g}$ soluble glass boluses (manufactured by Pilkington Controlles Release Systems Ltd., UK) administered with the other group not receiving a bolus to act as a control. Blood samples were taken by jugular venipuncture at days 0 (prior to bolus administration) and at days 30,60 and 90. The samples were analysed for copper status (serum caeruloplasmin activity and copper concentration), cobalt status (serum vitamin $\mathrm{B}_{12}$ concentration and cobalt concentration), selenium status (erythrocyte glutathione peroxidase activity and selenium concentration) and serum zinc concentration. The erythrocyte glutathione peroxidase activities, ceruloplasmin activities and vitamin $\mathrm{B}_{12}$ concentrations in serum were significantly increased for the bolused Bactrian camels $(\mathrm{P}<0.01)$ on all sampling days. The bolused camels had a significantly higher selenium and copper status in serum than the control Bactrian camels throughout the trial $(\mathrm{P}<0.01)$. The selenium and copper status of all the Bactrian camels was in the normal range. The selenium and copper status indicators indicate an adequate selenium and copper concentrations. There were no significant differences in zinc and cobalt concentrations between the bolused camels and the controls.
\end{abstract}

KEY WORDS: trace elements, controlled release, blood, Bactrian camel

\footnotetext{
* Supported by National Natural Science Foundation of China, Grants No. 30270993 and 30571364

${ }^{1}$ Corresponding author: e-mail: liuzongping@yzu.edu.cn
} 


\section{INTRODUCTION}

Bactrian camels (Camelus bactrianus) are vital to the production system of the Chinese desert and semi-desert areas where feeding resources are generally scattered and poor. These animals have adapted well to the harsh climatic conditions and poor feeding resources, not only providing hair, wool, meat and hides for local farmers and herdsmen, but also acting as an indispensable means of transport in this arid zone.

Essential trace elements are integral components of certain enzymes and of other biologically important compounds which play important physiological and biochemical roles, such that of selenium in glutathione peroxidase, copper and zinc in super oxide dismutase, iron in haemoglobin, cobalt in vitamin $\mathrm{B}_{12}$. Trace element deficiencies are common in ruminants, especially extensively grazed animals with access only grass and other naturally occurring plant material as their staple diet (McDowell, 1992; Liu et al., 1994; Lee et al., 1999). In the extensive situation, supplementing animals with trace elements can be difficult. Using supplemental feed as a trace element carrier incurs the costs of both feed and labour, if additional feed is not required. Free access minerals, mineral licks and blocks are subject to variable intakes with animals consuming between nothing and many times the required intake (McDowell, 1992). Oral dosing with trace element drenches is another possible alternative.

Controlled release intra-ruminal strategies, such as boluses or needles, provide relatively long-acting trace element supplementation. This form of supplementation does not require the animal to consistently consume supplementary feed, blocks, or free-access minerals and neither is the animal required to store the elements supplemented for later use. Although the strategy have been used in cattle and sheep (Telfer et al., 1984; Kendall et al., 2000, 2001; Qian et al., 2002), there are no data for Bactrian camels.

The trials reported were designed to study the effects of copper, selenium and cobalt soluble glass bolus on the copper, selenium, cobalt and zinc status of Bactrian camels.

\section{MATERIAL AND METHODS}

\section{Animals}

The sixty Bactrian camels, 30 females and 30 castrated males, selected for the study were 2-13 years of age in Alashanyouqi County of Inner Mongolia, at an altitude between 1200 and $1300 \mathrm{~m}$. They were grazed on desert and semidesert steppe throughout the year. The grassland vegetation is mainly puccinellia Chinampoensis ohuji, Siberian nitraria (Nitraria Sibirica pall), lovely achnatherum 
(Achnatherum splendens) (Trin) (Neuski), saxoul (Haloxylon ammodendron), desert wormwood (Artemisia desertorum), common ceratoides (Ceratioides lateens). All the animals were healthy, with no clinical signs of disease.

The camels were allocated to two groups by randomization. One group was dosed orally with two $100 \mathrm{~g}$ soluble glass boluses containing $13.4 \% \mathrm{w} / \mathrm{w}$ copper, $0.3 \% \mathrm{w} / \mathrm{w}$ selenium and $0.5 \% \mathrm{w} / \mathrm{w}$ cobalt (manufactured by Pilkington Controlles Release Systems Ltd., UK) and the other group left unbolused as a control group.

Blood samples were taken by jugular venipuncture at days 0 (prior to bolus administration) and at days 30,60 and 90. Serum samples for biochemical values were taken in tubes without anticoagulant and were refrigerated until they arrived at the laboratory in $<5 \mathrm{~h}$. The serum was separated by centrifugation $(1000 \mathrm{~g}, 10$ $\mathrm{min}$ ) and stored frozen in plastic vials.

Copper, zinc, cobalt were determined by atomic absorption spectrophotometry (AAS), while selenium was assayed by hydride generation atomic absorption spectrophotometry. The accuracy of the analytical values was checked by reference to certified values of elements in the National Bureau of Standards (NBS), Standard Reference Material, bovine liver SRM 1577a.

The serum content of ceruloplasmin $(\mathrm{Cp})$, erythrocyte glutathione peroxidase activity (GSH-Px) were determined on an automatic analyser using commercial test kits (Nanjing Medicine University Biochemical Co.). Serum vitamin $B_{12}$ concentration was determined by radioimmunoassay (RIA) using commercial test kits (Tianjing Medicine Biochemical Co.).

The data are presented as means \pm standard deviation. The differences between mean values in treated animals and controls were assessed by Student's t-test.

\section{RESULTS}

The erythrocyte glutathione peroxidase activities, ceruloplasmin activities and vitamin $\mathrm{B}_{12}$ concentrations in serum were significantly increased for the bolused Bactrian camels $(\mathrm{P}<0.01)$ on all sampling days (Table 1$)$.

Table 1. Serum biochemical values in Bactrian camels

\begin{tabular}{|c|c|c|c|c|c|c|c|c|}
\hline \multirow[b]{2}{*}{ Item } & \multicolumn{2}{|c|}{ Day 0} & \multicolumn{2}{|c|}{ Day 30} & \multicolumn{2}{|c|}{ Day 60} & \multicolumn{2}{|c|}{ Day 90} \\
\hline & $\begin{array}{c}\text { bolused } \\
30\end{array}$ & $\begin{array}{c}\text { control } \\
30\end{array}$ & $\begin{array}{c}\text { bolused } \\
30\end{array}$ & $\begin{array}{c}\text { control } \\
30\end{array}$ & $\begin{array}{c}\text { bolused } \\
30\end{array}$ & $\begin{array}{c}\text { control } \\
30\end{array}$ & $\begin{array}{c}\text { bolused } \\
30\end{array}$ & $\begin{array}{c}\text { control } \\
30\end{array}$ \\
\hline GSH-Px , U/ml PCV & 32.0 & 30.9 & $38.8^{\mathrm{a}}$ & 29.7 & $40.5^{\mathrm{a}}$ & 31.5 & $49.5^{\mathrm{a}}$ & 32.4 \\
\hline $\mathrm{Cp}, \mathrm{mg} / \mathrm{l}$ & 95.3 & 101.5 & $125.6^{\mathrm{a}}$ & 99.8 & $145.4^{\mathrm{a}}$ & 103.5 & $140.7^{\mathrm{a}}$ & 106.5 \\
\hline Vitamin $\mathrm{B}_{12}, \mathrm{pg} / \mathrm{dl}$ & 289.8 & 300.1 & $459.3^{\mathrm{a}}$ & 320.4 & $530.8^{\mathrm{a}}$ & 337.5 & $521.4^{\mathrm{a}}$ & 309.4 \\
\hline
\end{tabular}

${ }^{a} \mathrm{P}<0.01$ 
The bolused camels had a significantly higher selenium and copper status in serum than the control throughout the trial $(\mathrm{P}<0.01$; Table 2). The selenium and copper status of all the camels was in the normal range. The selenium and copper status indicators indicate an adequate selenium and copper concentrations. There were no significant differences in zinc and cobalt concentrations between the the bolused camels and the controls.

Table 2. Concentrations of trace elements in serum in Bactrian camels, $\mathrm{mg} / \mathrm{l}$

\begin{tabular}{lcccccccc}
\hline & \multicolumn{2}{c}{ Day 0 } & \multicolumn{2}{c}{ Day 30 } & \multicolumn{2}{c}{ Day 60 } & \multicolumn{2}{c}{ Day 90 } \\
\cline { 2 - 9 } Item & bolused & control & bolused & control & bolused & control & bolused & control \\
& 30 & 30 & 30 & 30 & 30 & 30 & 30 & 30 \\
\hline Selenium & 0.13 & 0.14 & $0.21^{\mathrm{a}}$ & 0.13 & $0.25^{\mathrm{a}}$ & 0.15 & $0.28^{\mathrm{a}}$ & 0.16 \\
Copper & 0.53 & 0.57 & $0.69^{\mathrm{a}}$ & 0.56 & $0.75^{\mathrm{a}}$ & 0.60 & $0.85^{\mathrm{a}}$ & 0.54 \\
Cobalt & 0.54 & 0.50 & 0.58 & 0.51 & 0.60 & 0.55 & 0.64 & 0.56 \\
Zinc & 10.7 & 12.5 & 12.8 & 11.7 & 12.2 & 13.4 & 11.6 & 12.4 \\
\hline
\end{tabular}

${ }^{\mathrm{a}} \mathrm{P}<0.01$

\section{DISCUSSION}

The Bactrian camles that received glass bolus had significantly increased selenium (GSH-Px), copper (Cp) and cobalt (vitamin $\mathrm{B}_{12}$ ) status at 30 to 90 days after treatment. This is agreement with the fingdings of Kendall et al. (2000, 2001a) in sheep. The boluses negate the need to supply these trace elements in free-access minerals, which can have variable intakes from zero to excessive (McDowell, 1992), or the supply of supplemental feed when only mineral supplementation is required. It is very difficult to give mineral supplementation for Bactrian camels in the Chinese desert and semi-desert areas, because of adverse natural environment and poor transport facilities. Bactrian camels are grazed on the desert steppe all day and night and the only effective way is to prevent trace elements deficiencies by providing an easy supplementation. The bolus has demonstrated a capacity to raise low selenium, copper and cobalt status of the camels to higher reference ranges. Bactrian camels with health problems likely to be caused or exacerbated by low selenium, copper and cobalt should benefit from receiving this type of bolus.

The controlled release bolus route should provide each animal with a consistent dose in line with its requirements sustained over a long period of time, such that one treatment should ensure adequate trace element cover for a number of months. Telfer et al. (1984) and Kendall et al. (2001b) reported that this type of bolus gave excellent results in field trails and has been previously shown to supply copper, cobalt and selenium in extensively grazed cattle and sheep for up to 345-days. 


\section{CONCLUSIONS}

The copper, selenium and cobalt soluble glass bolus increased the status of all three trace elements consistently for a period of at least 90 days. The bolus proved to be an appropriate method of increasing the selenium, copper and cobalt status of extensively grazed Bactrian camels. The bolus was able to prevent or correct deficient and/or marginal three trace element status of Bactrian camels.

\section{ACKNOWLEDGEMENTS}

My grateful thanks go to Mr. Zhang Youjia of Gansu Agricultural University, Mr. Yang Debin and Mr. Hu Qiande of the Animal Husbandry and Veterinary Station of Alashanyouqi County for their help in the sample collection. I would also like to acknowledge the assistance of the Head of Animal Husbandry and Veterinary Station of Alashanyouqi County for providing a car and camels as means of transportation and for the data on the area used in this study.

\section{REFERENCES}

Kendall N.R., Jackson D.W., Mackenzie A.M., Illingworth D.V., Gill I.M., Telfer S.B., 2001a. The effect of zinc, cobalt and selenium soluble glass bolus on the trace element status of extensively grazed sheep over winter. Anim. Sci. 73, 163-169

Kendall N.R., Mackenzie A.M., Telfer S.B., 2001b. Effect of copper, cobalt and selenium soluble glass bolus given to grazing sheep. Livest. Prod. Sci. 68, 31-39

Kendall N.R., McMullen S., Green A., Rodway R.G., 2000. The effect of a zinc, cobalt and selenium soluble glass bolus on trace element status and semen quality of ram lambs. Anim. Reprod. Sci. 62, 277-283

Lee J., Masters D.G., White C.L., Grace N.D., Judson G.J., 1999. Current issues in trace element nutrition of grazing livestock in Australia and New Zealand. Aust. J. Agr. Res. 50, 1341-1364

Liu Z.P., Ma Z., Zhang Y.J., 1994. Studies on the relationship between sway disease of bactrian camels and copper status in Gansu province. Vet. Res. Commun. 18, 251-260

McDowell L.R., 1992. Mineral in Animals and Human Nutrition. Academic Press, Inc. New York, pp. 26-76

Qian X., Liu Z.P., Qu Y.L., 2002. Effect of trace elements slowly releasing pellets on sheep. Chin. J. Vet. Sci. Technol. 6, 34-36

Telfer S.B., Zervas G., Carlos G., 1984. Curing or preventing deficiencies in copper, cobalt and selenium in cattle and sheep using tracerglass. Can. J. Anim. Sci. 64, Suppl., 234-235 